\title{
JUSTICIA POPULAR, DUALIDAD DE PODERES Y ESTRATEGIA SOCIALISTA *
}

\author{
Boaventura de Sousa Santos \\ (Facultad de Economia, Universidad de Coimbra)
}

Este trabajo parte de la constatación de que no existe una teoría marxista del Derecho y avanza una tentativa de explicación ausente en las vicisitudes del movimiento obrero de los paśses capitalistas en los últimos cien años. La reorientación estratégica que se considera necesaria y urgente presupone una sustentación global donde la teoría del Derecho deberá ocupar un lugar importante. Este estudio pretende ser una contribución modesta a una de las vías de acceso a ese trabajo de construcción teórica. Partiendo del concepto de dualidad de poderes tal como fue elaborado por Lenin y Trotski, procura conferirle simultáneamente mayor rigor analítico y mayor flexibilidad estratégica, de cara a aplicarlo a acciones populares dirigidas a sectores restringidos del aparato del Estado y sacando ejemplos de los casos de justicia popular en Portugal durante la crisis revolucionaria de 1974-1975. Yendo más lejos, intenta extender el concepto de dualidad de podetes a situaciones no revolucionatias en las que el conflicto entre el poder burgués y el poder obrero está de algún modo latente, dando como ejemplo el desarrollo y la práctica de un Derecho paralelo, no oficial, dentro de los barrios de chabolas de Río de Janeito.

* Este trabajo fue presentado originalmente al simposio sobre «Disciplina Capitalista y el Principio del Derecho», organizado conjuntamente por la «National Deviancy Conference» y la «Conference of the Socialist Economists» y celebrado en Londres los días 6 y 7 de enero de 1979. La traducción portuguesa fue hecha por Fernando Ruivo y revisada por el autor. La traducción al castellano fue revisada por Teresa Miralles y por Carlos Viladás. 


\section{INTRODUCCION}

La afirmación de que no existe una teorf́a marxista del Derecho se ha convertido casi en un lugar común, ${ }^{1}$ aunque sea reconocida con menor frecuencia la existencia de algunas teorías marxistas contra el Derecho de las que la más conocida sería la de Pashukanis. La razón usualmente invo cada para este déficit teórico ha sido la de que tanto el propio Marx como Engels sólo hicieron referencias dispersas e incompletas (no sistemáticas) al problema del Derecho en la sociedad capitalista. ${ }^{2}$ Se me antoja, sin embargo, teniendo en cuenta las mutuas implicaciones de las cuestiones teó-

1. Puede decirse lo tnismo respecto al Estado capitalista, a pesar de que, en este terreno, se ha ido desarrollando desde la década de los sesenta un vasto y sofisticado cuerpo de reflexión teórica tnarxista; lo que no impidió a Althusset - uno de los responsables principales, sin duda, de la renovación de los estudios marxistas sobre el Estado- de afirmat incluso tecientemente que «no existe realmente usa teoría marxista del Estado» (citado por Göran Therborn, «The Travail of Latin American Democracy», New Left Review, 113-114, 72). Dentro de 1a inmensa bibliografía de la Ǵltima década sobre el Estado, habrá que seguir una selección de los estudios que abrieton pistas importantes de investigacion: N. Poulantzas, Pouvoir Politique et Classes Sociales de l'Etat Capitaliste (París: Masperó, 1968); C. Offe, Strukturprobleme des Kapitalistischen Staates (Frankfurt, 1972); E. Altvater, «Zu einigen Problemen des Statsintetventionismuss, PROKLA 3, 1-53; $\mathrm{R}$. Miliband, The State in Capitalist Society (Londres, 1973); J. O'Connor, The Fiscal Crisis of the State (Nueva York, 1973); P. Anderson, Lineages of the Absolutist State (Londres, 1974); J. Hirsch, Staatsapparat und Reproduktion des Kapitals (Frankfurt, 1974); A. Negri, La Formo Stato (Milán, 1977); G. Therborn, What does the Ruling Class do when it Rules? (Londres, 1978); E. O. Wright, Class Crisis and the State (Londres, 1978). Pata el importante debate en la Alemania Fedetal ver, por últino, V. Brandes y otros (organizadores), Handbucb 5 Staat, Frankfurt, 1977; una perspectiva sobre el mismo debate en una lengua más accesible: J. Holloway y S. Picciotto, State and Capital. A Marxist Debate (Londres, 1978). Un debate no menos importante sobre el Estado en la América Latina puede verse, por último, en la Revisto Mexicana de Sociología, 1-2/77.

2. Aunque Marx no tesga elaborada una teoría del Derecho-como era, por otra parte, su intención-, lo cierto es que las referencias a este terna se encuentran dispersas en toda su obra y no solamente en los textoi que se suelen mencionar a este respecto. Trátase de una preocupación constante qut: se revela desde las primeras 
ricas y estratégicas en el marxismo, que la razón material para tal déficit debe hallarse en el hecho de que ninguna de las estrategias dominantes en el movimiento obrero ha necesitado verdaderamente, hasta la fecha, una teoría marxista del Derecho. Dejando por ahora a un lado los problemas relacionados con la distinción reforma/revolución, podemos identificar grosso modo dos estrategias principales: la estrategia revolucionaria (insurreccional), cuya formulación más corriente y global es de Lenin y fue la línea oficial de la Tercera Internacional, particularmente hasta 1934 1935 (comienzo del período de los frentes populares); y la estrategia reformista, a la que Eduard Bernstein proporcionó la reconstrucción teórica más elocuente y que correspondió a la práctica de los partidos de la Segunda Internacional hasta su colapso en 1914, antes de transformarse en la línea oficial del movimiento socialista salido de la escisión del movimiento obrero entre socialistas y comunistas en 1922-1923.

La estrategia revolucionatia pretende la destrucción del Estado capitalista a través de la confrontación global, incluyendo hasta la violencia, y sustituyéndolo por la dictadura del proletariado, una nueva forma estatal que surge de la lucha de los trabajadotes y que es adecuada a la prosecución de las tareas del período de transición al comunismo. En lo que se refiere a esta estrategia, el Derecho no desempeña un papel importante. $Y$ es que, siendo el Derecho un instrumento de dominación capitalista, ha de ser combatido del mismo modo que el Estado burgués. Y, de hecho, la tercera condición para la admisión en la Internacional Comunista postula que «los comunistas no pueden conflar en el Derecho burgués». Así se hace innecesaria la teorización al detalle de la posible utilización de la legalidad por la clase trabajadora; al contraxio, la teoría marxista del Derecho debe revelar la negatividad del Derecho frente al movimiento revolucionario. En este sentido, la teoría marxista del Derecho se transforma en una teoría marxista contra el Derecho. El mejor ejemplo es la teoría general del derecho de Pashukanis, ${ }^{3}$ aun prescindiendo de la importancia de sus argumentos para la elaboración de una teoría marxista del Derecho adecuada a las necesidades estratégicas del momento presente.

Por el contrario, la estrategia reformista se basaba en una extensa utilización del Derecho, ya que la transformación gradual del Estado capita-

colaboraciones en el Rheinische Zeitung hasta la Critica del Programa de Gotha. No es muy rico el trabajo de construcción teórica a partí de este vasto material, a pesar de que en las dos âlimas décadas se han hecho algunas tentativas de sistematización. Una de las primeras es la de U. Cerroni, Marx e il Diritto Moderno (Roma, 1962), y una de las últimas ia de M. Cain y A. Hunt, Marx and Engels on Law (Londres, 1979).

3. E. Pashukanis, A teoria Geral do Direito e o Marxismo (Coimbra, 1972). 
lista en Estado socialista ha de ser llevada a cabo a través de reformas sociales operadas en el interior del armazón constitucional vigente. Peto el empleo del Derecho sólo presupone una sofisticada teoría marxista del Derecho si cuando la gradual transformación del Estado es concebida como una gradual destrucción de la forma capitalista de Estado y como una emergencia también gradual de la nueva forma socialista de Estado. La estrategia reformista, sin embargo, tendió en la práctica a olvidar su finalidad estratégica, es decir, la transtormación y destrucción del Estado capitalista, concentrándose más bien en reformas sociales que, en el fondo, estabilizasen de hecho el Estado capitalista. Teniendo en cuenta esta práctica, la utilización del Derecho, lejos de presuponer una teoría marxista del Derecho, se ve guiada más adecuadamente por las teorías burguesas del Derecho que disponen de un vasto, tico y sofisticado cuerpo de pensa* miento jurídico orientado a la reproducción del Estado capitalista. El impasse de la teoría marxista del Derecho en el seno de esta estrategia ha sido muy bien ilustrado en la obra de Karl Renner. ${ }^{4}$ La crítica marxista de Renner al derecho de propiedad acaba con una visión apologética de las transformaciones estabilizadoras operadas por el Estado en el dominio del derecho capitalista de propiedad a comienzos del siglo xx.

A mi entender, una sofisticada teoría marxista del Derecho sólo se hace necesaria para una estrategia de la clase obreta basada en la superación de la dicotomía reforma/revolución tal como se manifiesta históricamente. Esto implicará la utilización no burguesa de la legalidad burguesa y la crea. ción y expansión de las instartcias de legalidad socialista alternativa. Aunque embrionarias, vacilantes y reversibles, existen señales de reorientación estratégica en esta dirección en toda Europa, tanto en el bloque del Este como en el Occidental, desde principios de los años sesenta. Tal teorientación está ligada a tres factores principales. En primer lugar, a las profundas modificaciones en el proceso de acumulación capitalista y a la estructura del Estado capitalista después de la Segunda Guerra Mundial. En segundo lugar, a la horrorosa experiencia del fascismo, con la consiguiente re-legitimación de los principios democtáticos en general. En tercer lugar, a los rasgos cada vez más visibles de una cierta degeneración del socialismo de Estado en la URSS y en los Estados europeos que se en. cuentran bajo su influencia, y la consiguiente reevaluación del papel (ambiguo) desempeñado por la URSS en el movimiento obrero europeo desde la fundación de la Tercera Internacional y, en particular, después de la subida de Stalin al poder.

4. K. Renner, The Institutions of Private Law and Tbeir Social Functions, (Londres, 1949). 
El fundamento teórico para tal reorientación estratégica en los campos del Derecho y del Estado debe basarse en tres tareas preliminates. Por un lado, el eliminar algunas construcciones seudoteóricas en ciertos tiempos veneradas. Por ejemplo, la metáfora topográfica base/superestructura, que ha de ser sustituida por un modelo de determinación más analítico y cons. cientemente materialista, es decir, más sensible a la estrategia y a la táctica. ${ }^{5}$ Por otro lado, aceptar el teto de releer, repensat y re-evaluar el período del movimiento obrero eutopeo entre 1890 y 1923, más o menos el período de la Segunda Internacional y los primeros años de la Tercera Internacional, en el curso del cual tuvo lugat el debate más rico, abierto y profundo en el interior del marxismo. Cuatro nombres se alzan con particular importancia para nuestro empeño teótico (especialmente a través de sus escritos menos conocidos). Me refiero a Karl Kautsky, Karl Korsch, Rosa Luxemburg y Eduard Bernstein, sobre todo los dos últimos. ${ }^{6}$ Puede parecer sotprendente e incluso chocante apuntar estos dos nombres conjuntamente, por ser tan conocido el hecho de que pertenecieron a alas opuestas de la socialdemocracia alemana. Transcurridos ochenta años, sin embargo, hay que leerlos y valorarlos teniendo en cuenta nuestras luchas y no las de ellos. Aparte de eso, y a pesar de lo que realmente les separó, compartieron algunos puntos de vista que son importantes para nuestros propósitos, en particular la idea del íntimo lazo existente entre democracia y combate socialista (comenzando en el mismo interior del partido de la clase obtera) y el principio de la democratización global de la vida social y política en la sociedad socialista. Finalmente, la tercera tarea preliminax consiste en analizar de nuevo luchas revolucionarias concretas, algunas de

5. El concepto de causalidad estructural elaborado por fa escuela aithusseriana constituye un avance positivo pero es todavía demasiado abstracto para poder servir de guía a los análisis científicos regionales, sobre todo en el campo del Detecho y del Estado. $\mathrm{La}$ investigación más reciente se otienta en el sentido del mayor rigor analítico, mexeciendo especial referencia el trabajo de Erik $O$. Wright.

6. K. Kautsky, Der Parlamentarismus die Volkgesetzgebung und die Sozialde. mokratie (Stuttgart, 1893); Patriotismus und Sozialdemokratie (Leipzig, 1907); Natio. nalität und Internationalität (1908); Nationalstat, Imperialistischer Staat und Staatenbund (Nürnberg, 1915); Von der Demokratie zur Stats-Sklaverei. Eine Auseinandersetzung mit Trotzki (Berlín, 1921); K. Korsch, Was is sozialisierung? (Kuannover, 1919); Quintessenz des Marxismus (Jena, 1922); Arbeitsrech für Betriebsräte (Berlín, 1922); Marxismus und Pbilosopbie (Leipzig, 1923); Der Weg der Komintern (Betlín, 1926); Um die Toriffäbigkeit (Berlín, 1928); Die Materialistiscbe Geschichtsauffasung (Leipzig, 1929); R. Luxemburg, Gesammelte Werke, 5 volúmenes (Dietzverlag, Berlín, 1972); E. Bernstein, Die Voraussetzungen des Sozialismus und die Aufgaben der Sozialdemokratie (1898); Zur Geschichte und Theorie des Sozialismus (1901); y, en general, su colaboración en periódicos, sobre todo en Sozialisticbe Monatshefte después de 1900 . 
ellas de tipo insurreccional, y en reelaborar los conceptos empíricos que de ellas se desprenden de cara a su posible utilización, en versiones transformadas y bajo condiciones diferentes, en contextos futuros. En este artículo me concentraré sobte esta última tarea, utilizando como ejemplo el concepto y las experiencias de dualidad de poderes en algunas revoluciones modernas, desde la rusa de 1917 a la portuguesa de 1974-1975. Empezaré por comentar la conceptualización de dualidad de poderes en Lenin y Trotski. Exploraté luego algunas posibles líneas de reconstrucción teórica del concepto, con un enfoque específico sobre el Derecho y la acción judicial. Me referiré finalmente a algunas utilizaciones estratégicas y tácticas de la dualidad de poderes en el Derecho y en la Administración de justicia, tanto en situaciones revolucionarias como no tevolucionarias.

\section{SOBRE LA «DUALIDAD DE PODERES》}

Para Lenin, la dualidad de poderes es «una particularidad extremada. mente notable» ${ }^{7}$ de la revoluxción rusa y "la peculiaridad esencial de nuestra revolución, peculiaridad que requiere más impetiosamente una atención reflexiva». ${ }^{8}$ Consiste "en que al lado del gobierno provisional, el gobierno de la burguesía, se formó otro gobierno, todavía débil, embrionatio, pero sin duda de hecho existente y en desarrollo - - los soviets de diputados obreros y soldados». ${ }^{9}$ Respecto a la cuestión de la composición de clase de este otro gobierno, Lenin aclara que está compuesto por el «proletariado y los campesinos vestidos con el uniforme de soldados. ${ }^{10}$ En lo que se tefiere a la naturaleza política de este gobierno, Lenin afirma: «Es una dictadura revolucionaria, es decir, un poder que se apoya directamente en la conquista revolucionaria, en Ia iniciativa inmediata de las masas populares venida de abajo, y no en la ley promulgada por un poder de Estado centralizado. Es un poder de un género completamente diferente del poder que generalmente existe en las repúblicas parlamentarias democráticoburguesas del tipo habitual imperante hasta ahora en los países avanzados de Europa y de América. Esta circunstancia es olvidada con frecuencia, no se medita sobre ella, a pesar de que en ella teside toda la esencia del problema. Este poder es un poder del mismo tipo que el de la Comuna de París de 1871. Los rasgos fundamentales de este tipo son: 1. La fuente del poder no está en una ley previamente discutida y aprobada por el

7. V. I. Lenin, Obras escclbidas (Lisboa, 1978), vol. 2, p. 17.

8. Ibid..., p. 24.

9. Ibid..., p. 17.

10. Ibid..., loc. cit. 
Parlamento, sino en la iniciativa directa de las masas populares partiendo de abajo y a escala local, en la "conquista» directa, para emplear una expresión corriente. 2. La sustítución de la policía y del ejército, como instituciones separadas del pueblo y opuestas al pueblo, por el armamento directo de todo el pueblo; con este poder el orden público es mantenido por los propios obreros y campesinos armados, por el propio pueblo ar. mado. 3. El funcionario, la burocracia, o bien son sustituidos también por el poder inmediato del propio pueblo o bien, por lo menos, son colo cados bajo un control especial y se transforman en personas tho sólo elegibles, sino también destituibles a la primera exigencia del pueblo y se reducen a la situación de simples representantes, transfórmanse de clase social privilegiada, con «puestecillos» de remuneración elevada, burguesa, en obreros de un «arma» especial, cuya temuneración no exceda del salario normal de un buen obrerow."

Escribiendo en abril, Lenin reconoce que los soviets son una forma de Estado embrionario e incipiente. Además de ello, debido a la influencia de elementos pequeñoburgueses (mencheviques y socialistas revolucionarios), el poder de los soviets, al establecer un acuerdo de apoyo al gobierno provisional y al hacer concesiones de hecho, «cedió y cede él mismo posiciones a la burguesían. 12

Estas circunstancias extremadamente peculiares de Ia revolución rusa "que la Historia no había conocido todavía bajo tal forma», dieron origen a un «entrelazamiento en un todo único de dos dictaduras: la dictadura de la burguesía... y la de los proletarios y campesinos».13 Pero no hay la menor duda de que un tal «entrelazamiento» no puede durat mucho. No pueden existir dos fuerzas en un Estado. Una de ellas está condenada a desaparecer. «La dualidad de poderes no expresa sino un momento de transición en el desarrollo de la revolución cuando ésta traspasó los límites de la revolución democrático-burguesa común pero no le gó aún a una dictadura "pura del proletariado y del campesinado"..1 ${ }^{14}$

La caracterización de la cualidad de poderes efectuada por Trotsky es a la vez más amplia y optimista. Contrariamente a Lenin, Trotsky ve la situación de la dualidad de poderes como una «condición distinta de crisis social en modo alguno exclusiva de la revolución rusa de 1917 , aunque se halle en ésta más claramente caracterizada» ${ }^{15}$ Después de especificar que no nos encontramos ante una dualidad de poderes en las situaciones

11. Ibid..., pp. 17-18.

12. Ibid..., p. 18.

13. Ibid..., p. 25.

14. Ibid..., p. 26.

15. Trotsky, The Basic Writings of Trotsky (Nueva Yotk, 1963), p. 101. 
en las que el poder de la clase dominante se ve compartido entre dos de sus facciones, como las de los junkers alemanes y la burguesía (ya sea bajo los Hohenzollern, ya sea en la república), Ttotsky agrega que tal dualidad «no presupone - - generalmente hablando, incluso excluye-- la posibilidad de división del poder en dos partes iguales o cualquier equilibrio formal de fuerzas. No se trata de un hecho constitucional, sino revolucionario. Implica que la destrucción del equilibrio social ha resquebrajado ya la superestructura estatal. Surge en situaciones en que clases hostiles que se basan en organizaciones de gobierno esencialmente incompatibles - una que sobrevive, otra en proceso de formación--, se atropellan en cada grado de la esfera de gobierno. La suma de poder que, en estas situaciones, recae sobre cada una de estas clases en lucha está determinada por la correlación de fuerzas en el transcurso del combate». ${ }^{16} \mathrm{La}$ situación de dualidad de poderes puede llevar a la guerra civil en el caso en que esa dualidad asuma una expresión territorial y se haga entonces aún más visible. «Pero antes de que las clases y los partidos rivales lleguen a tal extremo... pueden sentirse obligados por mucho tiempo a soportar e incluso a sancionar el sistema de dos poderes.» ${ }^{17}$ Trotsky ilustra enronces la situación de dualidad con referencia a las revoluciones inglesa, francesa, alemana y rusa. En lo que se refiere a la revolución tusa, la especificidad de su dualidad de poderes reside en el hecho de que, contrariamente a las anteriores, «vemos a la democracia oficial crear consciente e intertcionalmente un sistema de doble poder, evitando a toda costa asumir el poder solas. ${ }^{18}$ Así, la dualidad de poderes comienza de forma disimulada y sólo emerge a la superficie cuando los bolcheviques sustituyen a los conciliadores en la dirección de los soviets. Trotsky concluye que «la peculiaridad básica de la revolución rusa reside en la madurez inconmensurablemente superior del proletariado ruso en comparación con las masas urbanas de las antiguas revoluciones. Aquella condujo a la paradoja de un doble gobierno semifantasmal y, más tarde, impidió que su parte real cayera en manos de la burguesías."9

Las diferencias entre Lenin y Trotsky sobre la cuestión de la dualidad de poderes pueden estar relacionadas muy probablemente con los diferentes contextos en que escribieron: por un lado, una narración política escrita en 1917 sobre los acontecimientos; por otro, un análisis histórico producido entre 1930 y 1932 en la isla de Prinkipo. En cualquier caso, sin embargo, tales escritos tienen mucho en común y revelan las siguientes características generales inherentes a la dualidad de poderes:

16. Ibid..., p. 103.

17. Ibid..., loc., cit.

18. Ibid..., p. 107.

19. Ibid..., p. 109. 
a) Ocurre en una crisis revolucionatia, en una situación de intensa lucha de clases en que la cuestión de la transformación radical de la sociedad se convierte en un problema político "práctico», «realista».

b) Existe una pluralidad de centros de poder político surgido de las contradicciones existentes entre las clases en lucha y no de divisiones en el interior de cualquieta de las clases en presencia.

c) La fuente de la legitimidad del poder de la clase (proletaria) emergente no reside en el Derecho producido por un gobierno centralizado, sino en la «legalidad revolucionaria»o, utilizando la terminología de Lenin, «en la conquista revolucionaria, en la iniciativa inmediata de las masas populares venidas de abajo». ${ }^{20}$ Tal iniciativa puede ser tan «directa» que puede incluso llegar a sorprender a los «tevolucionarios profesionales», ya que, como de buena fe confiesa Lenin, «es preciso saber completar y corregir las viejas "fórmulas", por ejemplo las del bolchevismo, porque, como se demostró, fueron en general acertadas, pero su realización concreta se reveló diferente. Nadie pensaba antes, ni podía pensar, en la dualidad de poderes». ${ }^{21}$

d) Las diferencias en la base social de apoyo y en el desarrollo institucional entre los dos poderes polares pueden ser más o menos visibles y se encuentran en continua mutación.

e) Los poderes en conficto se hallan en una situación de confrontación global o, cuanto menos, tienden a ello, ya que, en las etapas iniciales, ciertos factores tales como la insuficiente conciencia de clase pueden forzar al poder emergente a compromisos o concesiones.

f) Los dos poderes representan no solamente intereses de clase contradictorios, sino también formas contradictorias de Estado: una democra. cia parlamentaria contra un tipo de gobierno idéntico al de la Comuna de Patís.

g) La dualidad de podetes es siempre una situación inestable porque la división de poder que acarrea tiene tendencia a resolverse a favor de una de las clases en lucha.

La conversión de la dualidad de poderes en una dimensión universal de la situación revolucionaria operada por Trotsky contribuyó a una mayor comprensión de otras revoluciones del siglo xx: la de Alemania en 1917 $1923,{ }^{2}$ Ia de España en $1936-1939^{23}$ y las de varios países de América La-

20. Lenin, Obras..., op. cit, p. 17.

21. Ibid..., loc. cit.

22. Pierre Broué, Révolution en Allemagne (1917-1923), (París, 1971).

23. P. Broué y E. Témime, La Revolution et la Guerre d'Espagne (París, 1961). 
tina. ${ }^{24}$ Se hace ahora inperioso reelaborar o transformar el concepto de dualidad de poderes con el fin de enriquecer su contenido analítico y adaptarlo a las perspectivas estratégicas de la revolución socialista en la Europa de hoy. Teniendo esto en cuenta, paso ahora a la discusión de los tesultados de la dualidad de poderes en el contexto de la revolución portuguesa de 1974-1975.

\section{EXPERIENCIAS DE LA REVOLUCION PORTUGUESA}

No es éste el lugat para dar cuenta de lo que fue la revolución portuguesa. Es muy probable incluso que los historiadores del futuro lleguen a negar el estatuto de verdadera revolución a lo que aconteció en Portugal en 1974-1975, tal como lo hicieron con la revolución alemana de noviembre de $1918 .^{25}$

La revolución portuguesa comenzó con una revuelta militar conducida por un considerable grupo de jóvenes oficiales demócratas y antifascistas deseosos de acabar con la guerra colonial. En lo referente al proyecto político para el continente, el programa del Movimiento de las Fuerzas Armadas (MFA) era inequívoco, a pesat de su generalidad: destrucción inmediata de las características fascistas del aparato de Estado; elecciones para una Asamblea Constituyente donde la democracia parlamentaria debía ser restaurada; pluralismo político y autonomía de las organizaciones de la clase obrera; una política económica antimonopolista, apuntando hacia una distribución más equitariva de las riquezas. En lo que atañe, sin embargo, a la cuestión colonial, el programa era bastante ambiguo. Apelaba a una solución política en el ámbito de un vasto espacio portugués. Tal ambigüedad era la consecuencia del hecho de que los jóvenes oficiales habían sido compelidos a comprometerse con Spínola, uno de los dos generales que entró en conflicto con el gobierno de Marcelo Caetano. El compromiso fue considerado entonces importante, no sólo para minimizar la posibilidad de resistencia de algunas unidades militares leales al antiguo régimen, sino también para anular cualquier tentativa de declaración unilateral de independencia por parte de la población blanca de las colonias, particularmente en Angola.

Spínola representaba claramente los intereses del capital monopolista, en tanto que los oficiales jóvenes del MFA recibieton desde el principio

24. R. Zavaleta Metcado, El poder dual en América Latina (México, 1974).

25. P. Broué, Révolution..., op. cit., p. 161. 
un tremendo apoyo popular por parte de la clase obrera y de amplios sectores de la pequeña burguesía.

La movilización popular que siguió (huelgas de carácter económico y político estallaton por todo el país) fue el factor determinante de la derrota total de Spínola, así como de la neutralización de los elementos derechistas en el seno del MFA y de la radicalización política de sus elementos más progresistas. Este hecho, asi como el firme rechazo de cualquier solución de tipo spinolista para la cuestión colonial por parte de los dos principales movimientos de liberación, constituyeton las precondiciones esenciales para lo que llegaría a ser el proceso de descolonización de los tiempos modernos más exento de rasgos neocolonialistas.

Las alteraciones cualitativas en el proceso político tuvieron lugar después de marzo de 1975 , cuando la sociedad portuguesa entró en una ctisis revolucionaria: amplia nacionalización de la industria; nacionalización total del sistema bancario y de seguros; ocupaciones de tierras en el Alentejo; ocupaciones de casas en las grandes ciudades; consejos obreros; autogestión de empresas industriales y comerciales abandonadas por los antiguos propietarios; cooperativas en la industria, en el comercio y en la agricultura; asociaciones de vecinos; clínicas del pueblo; dinamización cultural en las tegiones más atrasadas del país. Ninguna de estas medidas, tomada indi. vidualmente, ponía en cuestión las bases capitalistas de la sociedad o la naturaleza de clase del poder del Estado. Sin embargo, todas ellas, en su conjunto maliadas a la dinámica interna de la movilización de la clase obrera y de la iniciativa popular, a la parálisis generalizada de los aparatos del Estado y al creciente conflicto en el interior de las fuerzas armadascausaron, de hecho, una crisis revolucionaria. Pero en ningún momento se estuvo ante una situación de dualidad de poderes concebida como «confrontación global» entre «dos dictaduras». Aunque un análisis detallado de este hecho esté todavía por hacer, me parece que uno de los factores más directamente causales residió en la propia naturaleza de los acontecimientos que condujeron a la crisis revolucionaria. Todo comenzó con una revuelta militar, es decir, una tevuelta venida desde arriba, producida en el propio seno del aparato de Estado. Tratábase de destruir el poder de Estado fascista, pero, en realidad, sólo fueton eliminadas las características del Estado más explícitamente fascistas tales como la policía política, las prisiones y los tribunales políticos, el sistema de un solo partido y las milicias paramilitares fascistas. Aparte de eso se manturvo intacto el aparato de Estado, con sus cincuenta años de ideología, institucionalización, reclutamiento, entrenamiento y práctica autoritarios. A pesar de que, bajo presión popular, se hubiesen registrado algunos saneamientos de cuadros en la Administración pública y en la industria, fueron cuantitativamente limita* 
dos, frecuentemente oportunistas y, en ciertos sectores cruciales del aparato de Estado (como la Administración de justicia, por ejemplo), virtualmente inexistentes. De todos modos, los saneamientos se limitaron siempre a los cuadros de personal y no llegaron nunca a alcanzar las estructuras del poder de Estado. En cuanto a las dos ramas del aparato represivo del Estado - policía (PSP y GNR) y fuerzas armadas- la situación fue aún más evidente. Ya que la policía no ofreció resistencia a los jóvenes oficiales del MFA, se hizo innecesario desmantelar, ni siquiera reestructurar, la organización; únicamente fucton sustituidos los oficiales de mayor graduación. En lo que atafie a las fuetzas armadas, no queda ninguna clase de duda de que éstas se vieron sacudidas hasta las taíces; pero precisamente por haberse originado la revuelta entre sus filas y por haberse mantenido el proceso político bajo control militar, se sintieron globalmente legitimadas de nuevo y suspendieron cualquier teestructuración interna profunda. Esto explica, entre otras cosas, el hecho de que los comités de soldados apareciesen tan tarde en el proceso, minados por intereses partidarios y sectarios y sin ninguna dinámica interna.

Resumiendo, una vez suptimidas sus características distintivamente fascistas, el aparato de Estado no se colapsó. Sufrió más bien una parálisis general. En la medida en que los acontecimientos políticos inmediatos habran sutgido en su seno (en el interior de uno de sus aparatos), se hacía «relativamente fácil» llevar a cabo la parálisis del poder de Estado burgués. En este sentido no existía un dominio político efectivo por parte de la burguesía. Pero por las mismas tazones tampoco existía un dominio político efectivo por parte del proletariado. El papel desempeñado en este contexto por los grandes partidos de la clase obrera (PS y PCP) debe ser mencionado brevemente. Hahiendo obtenido una considerable influencia en el aparato de Estado y en el interior de las fuerzas armadas inmediatamente después de marzo de 1975, el PCP (en aquel tiempo, la única organización política digna de tal nombre) se mostró siempte teticente frente a la movilización espontánea y a la organización creativa de la clase obrera tanto a nivel de la producción como de la reproducción. Utilizando el argumento engañoso de que el enemigo ya había sido destruido a través de la nacionalización del capital monopolista y de que el sector del MFA entonces en el poder, si era apoyado, pondría en primer lugar los intereses del proletariado, el PCP favoreció planes de acción en el interior del aparato de Estado y retrocedió ante la idea de la construcción de un auténtico poder popular. Por su parte, el Pattido Socialista, de reciente formación y composición heterogénea (bajo el dominio del sector socialdemócrata) se resintió de la infuencia de los comunistas en el aparato de Estado y rechazó, como parte integrante de su lucha antitotalitaria, cualquier fórmula política 
que no fuese la democracia parlamentaria. Apoyado por la burguesía y por sectores de la pequeña burguesía y de la clase obrera (desarticulados a nivel nacional por una estructura productiva desequilibrada y no integrada; sin gran experiencia organizativa; tesentidos con el poder político y la arrogancia de los comunistas; bloqueados por una ideología católica retrógrada), el Partido Socialista se transformó en seguida en el partido de la oposición par excellence. Al igual que en la Alemania de 1918, los socia. listas se convirtieron en el partido principal de una amplia coalición en la que sobresalian fuerzas sociales burguesas y conservadoras que, acto segui. do, maniobraron para dejarlos en plano subalterno.

Puede afurmarse que el mismo proceso que obtuvo rápidamente la suspensión o neutralización del poder burgués impidió simultáneamente que el poder del proletariado surgiese en su propio nombre. Fue menos una situación de dualidad de poderes que de dualidad de impotencias, como yo la caracterizaría, una situación que se resolvió a favor del poder burgués en noviembre de 1975. En verdad, la tevolución portuguesa demuestra, como una de sus características más notables, que el Estado burgués puede sufrir una parálisis general por un largo período de tiempo sin alcanzat el colapso. Por el contrario, se conserva intacto como una especie de reserva estatal para ser reactivado tan pronto como las relaciones de fuerza cambien a su favor.

Dentro de esta situación global de impotencia dual que acabo de describir surgieron formas restringidas de dualidad de poderes en áreas específicas de la vida social y en sectores específicos del aparato de Estado. Uno de esos casos de poder dual se produjo en el aparato judicial y asumió la forma de justicia popular. Describí y analicé detalladamente en otro lugar los principales casos de justicia popular en Portugal ocurtidos entre marzo y noviembre de $1975 .^{26} \mathrm{El}$ más conocido, aunque no el más característico, fue el caso Diogo. José Diogo, trabajador rural del Alentejo, fue acusado de haber asesinado a un gran latifundista, antiguo patrón suyo y presidente del consejo municipal durante muchos años. Debido a la creciente solidaridad populat con Diogo, el caso fue transferido del tribunal local al de Lisboa, pues "el clima emocional en torno del caso", pata utilizar las pałabras del delegado del fiscal, no permite una administración de justicia «independiente y ordenada». Por las mismas razones, el caso fue nuevamente transferido, esta vez a Tomar, pequeña ciudad situada a $100 \mathrm{~km}$ al norte de Lisboa. Se produjo entonces una situación altamente

26. B. Santos, «Law and Revolution in Portugal: The Experiences of Populat Justice after the 25th of april 1974», trabajo presentado originalmente al IV Congreso del European Group for the Study of Deviance and Social Control (Viena, 1976) y a publicar en Politics and Society en 1979. 
confusa en la que la justicia oficial parecía al borde del colapso: pese a encontrarse en prisión preventiva, José Diogo no pudo comparecer ante el tribunal por decisión de las autoridades carcelarias (zobedeciendo órdenes superiores?); en contra de decisiones anteriores dentro del mismo proceso, el teo fue liberado bajo fianza y el importe de la misma fue obtenido en pocas horas mediante peticiones transmitidas por radio. En este contexto, en el día y en el local determinados para su juicio oficial, José Diogo fue juzgado en la escalinata del Palacio de Justicia por un jurado popular autonombrado y compuesto por trabajadores industriales y rurales. Después de haber hablado mucha gente, particularmente trabajadores rutales, denunciando el poder despótiç de los grandes señores rurales del Alentejo, así como las condiciones opresivas en que el proletariado rural se veía obligado a vivir, el latifundista fue "condenado póstumamente» por el jurado «por haber oprimido y explotado» al pueblo alentejano; al mismo tiempo, después de haber examinado las condiciones extremas en que había actuado José Diogo, el mismo jurado le absolvió, pese a considerat que, siendo individual la actuación del reo, no podía ser considerada ni justificada como revolucionaria.

La mayor parte de los demás tribunales populares trató de cuestiones de vivienda. El más conocido fue el caso Maria Rodrigues. Maria Rodrigues ocupaba una casa ilegalmente. La propiedad entabló un proceso contra ella y el juicio fue señalado para noviembre de 1975. El secretariado de las comisiones revolucionarias de vecinos, actuando en nombre de Maria Rodrigues, boicoteó la sesión del juicio y organizó un jurado popular compuesto por 28 delegados de varias comisiones. Este jurado se teunió en el patio interior del Palacio de Justicia y, después de largas horas de discusión sobre la cuestión de la vivienda, concedió a Maria Rodrigues el derecho de permanecer en la casa que había ocupado. Se organizaron entonces comités de vigilancia con vistas a impedir cualquier tentativa de lanzamiento por parte de la policía.

Todos estos casos son formas muy embrionarias y pobremente organizadas de justicia popular y, por lo tanto, de dualidades de poderes en el área judicial. No obstante, apuntan a una forma jurídica y a una legalidad revolucionarias. Así, las fronteras normativas de los casos se transforman de manera que el contenido de clase de la disputa judicial -n-siempre encubierto por la legalidad burguesa- se haga aparente. El objeto de la disputa se amplía así inmensamente y el desfase entre la disputa «real» y la disputa «procesada» -característica del proceso burgués-r- es eliminado. Además, las relaciones de clase en la disputa se invierten. El jurado popular, organizado sobre la base de la posición de clase y no sobre la de la ciudadanía abstracta, se asume a sí mismo como la justicia de las clases 
oprimidas; en consecuencia, el reo en el tribunal estatal se transforma en demandante o actor en el tribunal popular y viceversa. El efecto de aislamiento - también característico de la justicia burguesa- desaparece, pues ambas partes acuden al tribunal no ya como individuos abstractos, sino más bien como miembros de una clase. Se conserva la forma del juicio, pero no sólo se modifica la estructura del jurado, sino que también las reglas que definen la materia relevante de la causa son completamente subvertidas. Las acciones de José Diogo y de Maria Rodrigues hallan su contexto en la historia de la lucha de clases en el Alentejo y en los gbettos urbanos, tespectivamente, y son valoradas de modo diferente a la luz de su diferente significado en estas luchas. Por otra parte, no hay distinción rigurosa entre las cuestiones sustantivas y procesales; el principio de la imparcialidad del juicio queda mediatizado por el reconocimiento de que la disputa llevada a juicio es la cima del iceberg, un pequeño detalle de una lucha de clases mucho más vasta donde el enemigo de clase no se presume nunca inocente. Por último, no hay monopolización profesional del proceso judicial ni expropiación técnica del discurso y del lenguaje jurídicos.

Ya que estos casos limitados de poder dual, como muchos otros en otras áreas de la vida social (industria, educación, prisiones, etc.) tuvieron lugar en una situación global de impotencia dual, consistieron siempre en acciones fragmentarias y, como tales, no pudieron ser reproducidas de modo acumulativo. En la medida en que no existía una estrategia revolucionaria unificada capaz de llevar al poder al proletariado, las iniciativas de poder dual no pudieron progresar hacia una confrontación global con el poder de Estado burgués. El poder de Estado paralizó pero permaneció virtualmente indiviso. Esto explica la tazón por la que el aparato judicial del Estado no perdiera nunca el control, sea en el caso Diogo o en el caso Rodrigues. En realidad, después del 25 de noviembre de 1975, cuando las condiciones para la activación del poder burgués futeron restauradas, los dos casos fueron juzgados en los tribunales oficiales y ambos reos fueron considerados culpables. $\mathrm{Y}$ aunque aquí no trate de esta cuestión, es altamente discutible si los casos específicos de justicia popular desempeñaron un papel positivo o negativo en las condiciones específicas de la revolución portuguesa.

\section{ANALISIS DE UN CASO BRASILEÑO}

Los casos de justicia popular en la revolución portuguesa representan una doble contribución a la estrategia revolucionaria. En primer lugar, 
muestran que, para eliminat las abertaciones históricas que rodean la idea de justicia popular (por ejemplo, los Volksgericbte de Hitler), ésta ha de ser concebida como dualidad de poderes en la función judicial, como justicia de la clase obrera contra la justicia de la burguesía. En segundo lugat, ilustran uno de tos modos posibles de transformación del concepto de poder dual con el fin de aumentar su valor analítico y estratégico: cuando las condiciones especificas de crisis revolucionaria no permiten una confrontación global con el viejo poder de Estado, es posible, y en ciertos casos correcto, crear formas limitadas o sectoriales de poder dual que operen en las áreas particulares de vida social o en sectores particulares de la acción estatal.

Es posible sin embargo pensar en otros modos de transformar el concepto de poder dual de maneta que se abarque tanto la diversidad compleja como la dinámica de la lucha socialista en nuestro tiempo. En los casos presentados hasta ahora el poder: dual tuvo lugar en una crisis revolucionatia $y$, pese a manifestarse bajo forma sectorial restringida, incorpora una situación de enfrentamiento entre poderes antagónicos, es decir, una situación de conflicto interclasista. Es concebible, no obstante, la utilización del concepto de poder dual - de forna debilitada pero no por ello menos válida-en situaciones no revolucionarias, englobando poderes más complementarios o paralelos que enfrentados, en las que dominan, cuando menos en la superficie, los conflictos intraclasistas. Trataré de demostrar tal posibilidad -restringida en el presente trabajo al poder dual en el ámbito del Derecho y de la justicia - refiriéndome a las funciones judiciales desempeñadas por las asociaciones de vecinos de los barrios de chabolas de las grandes ciudades del mundo capitalista y presentando como ejemplo el caso de la asociación de vecinos de uno de los mayores barrios de chabolas de Río de Janeito que tuve ocasión de estudiar en profundidad. ${ }^{27}$ Pasargada, nombre que doy en mi trabajo a esta favela (designación dada en el Brasil a los barrios de chabolas), es un barric viejo y grande, marginal tespecto a Río, instalado en un vasto terreno que en los tiempos de la ocupación inicial (principios de los años treinta) era propiedad privada, siendo hoy propiedad del Estado. Desde hace algunos años; la comunidad viene eligiendo una asociación de vecinos formalmenze encargada de representar los intereses de la comunidad frente a los varios departamentos estatales, particularmente en lo que respecta a servicios públicos y equipamientos colectivos, y de promover la convivencia pacífica en el interior de la favela. $\mathrm{Mi}$ investigación reveló, sin embargo, que más allá de estas funciones nor-

27. B. Santos, Law Against Law: Legal Reasoning in Pasargada Law (Cuernavaca, 1974); (The Law of the Oppressed: the Construction and Reproduction of Legality in Pasargadas, Law and Society Review, vol. 12, 5-1226. 
males -que son, como sería de prever, pobremente ejecutadas dada la sobreexplotación de las capas populares, la legislación represiva y el poder político de tipo fascista en el Brasil de hoy- la asociación de vecinos se había transformado gradualmente en un forum judicial, un instrumento de prevención y resolución de conllictos en el interior de Pasargada. En este terreno, la asociación ejerce hoy dos tipos de funciones: ratificación de telaciones juxídicas y resolución de las disputas que surgen de ellas. Las relaciones jurídicas se originan usualmente en contratos (ventas, arrendamientos, etc.) cuyo objeto es la propiedad, la posesión y los derechos teales sobre la tierra y las viviendas (casas y barracas) o parte de ellas. Pero la asociación también desempeña funciones con respecto a relaciones de Detecho público, concernientes a los derechos de la comunidad como un todo frente a alguno o algunos de sus miembros. Cutando, por ejemplo, los vecinos desean celebrar un contrato, pueden acudir a la asociación y entrevistarse con el presidente. Vienen, normalmente, acompañados por farmiliates, amigos o vecinos, algunos de los cuales servirán de testigos. Las partes explican sus intenciones al presidente, el cual formula preguntas relativas a la naturaleza del contrato y a su objeto hasta formarse una idea clara. Entonces el contrato es puesto por escrito y archivado, distribuyéndose copias a las partes intervinientes. La intervención de la asociación, que designo como ratificación, es un proceso muy sutil y complejo a través del cual la relación jurídica entre las partes se provee de una fuente autónoma de seguridad. Cuando estalla un conflicto entre dos vecinos, la asociación puede ser llamada a tesolverio, dando comienzo a un proceso que termina en la discusión de la cuestión por las partes y los vecinos en una audiencia dirigida por el presidente.

Analicé con detalle las estructuras normativas y retóricas de esta legalidad comunitaria a la que llamé derecho de Pasargada y que cubre una interacción jurídica muy intensa y compleja, marginal al sistema jurídico estatal (el derecho del asfalto, como le llaman los habitantes de las favelas). ${ }^{23}$ Como es obvio, el derecho de Pasargada sólo es válido en el seno de la comunidad, ya que, desde el punto de vista de la legalidad estatal, todas las transacciones basadas en la tierra ilegalmente ocupada no poseen validez legal. La estructura normativa de Pasargada se basa así en la inversión de la norma básica (grundnorm) de la propiedad a través de la cual el estatuto legal de la tierra de Pasargada es consecuentemente invertido: la ocupación ilegal se transforma en posesión y propiedad legales. Efectuada esta inversión, las normas de propiedad del derecho del asfalto pue-

28. Law Against Law, op. cit., pp. 277 y ss.; "The Law of the Oppressed», cit., pp. 38 y ss. 
den ser selectivamente incorporadas al derecho de Pasargada y aplicadas en la comunidad. De hecho, el principio de la propiedad privada y las consecuencias legales que acarrea son tan respetadas en el derecho de $\mathrm{Pa}$ sargada como en el derecho oficial brasileño. El discurso legal cuenta en Pasargada con una retórica jurídica muy rica y elaborada. ${ }^{29}$ Comparando la argumentación jurídica de Pasargada con la que prevalece en la justicia estatal contemporánea es tal vez posible demostrar que, en un aparato legal dado, la intensidad del uso de la retórica jurídica tiende a variar en razón inversa a la fuerza efectiva de los poderes de coerción y de teptesión al servicio de aquel aparato. $Y$, en verdad, el derecho de Pasargada es una forma de legalidad muy embrionaria y precaria y la asociación de vecinos coexiste en la comunidad con otros centros de poderes, siendo muy limitados sus poderes de coerción. Es también un armazón legal extremadamente accesible, participativo y no profesionalizado. La distinción entre cuestiones procesales y sustantivas no se encuentra rígidamente establecida y la mediación es el modelo dominante de la resolución de los conflictos. ${ }^{30}$

Aunque precario, el detecho de Pasargada tepresenta una legalidad alternativa a la legalidad estatal butguesa y, en este sentido, también representa el ejercicio, aunque débil, de una forma alternativa de poder. En la medida en que el derecho de Pasargada no reclama validez o eje. cución fuera de la comunidad y solamente intenta resolver conflictos intraclasistas, los dos poderes legales (el derecho del asfalto y el derecho de Pasargada) no entran en confrontación. Son más bien paralelos e incluso complementarios. Asimismo es concebible aplicar el concepto de poder dual, en esta forma debilitacia, a la relación desigual entre el derecho de Pasargada y el derecho del asfalto.

Puede objetarse que tal aplicación constituye una extensión ilegítima del concepto de dualidad de poderes, pues el derecho de Pasargada no hace más que prolongar el detecho estatal en el seno de la comunidad $y$, por esta razón, es probablemente funcional para los objetivos generales de la dominación burguesa (en la medida en que asegura la reproducción pacífica y a bajo coste de la fuerza de trabajo). Aunque parcialmente de acuerdo con esta objeción, me gustaxía contraargumentarla con tres observaciones. Primeramente el derecho de Pasargada, al producir una legalidad alternativa, intenta neutralizar o contrariar el hecho de que en las sociedades capitalistas (al menos en las de la periferia) las clases trabajadoras

29. Uno de los principales vectores teóricos de los trabajos citados en la nota 27 consiste en el aprovechamiento y el cesarrollo sociológicos de los estudios de retórica jurídica tradicionalmente apropiados para la filosofía del Derecho.

30. Law Against Law, op. cit., pp. 324 y ss.; "The Law of the Oppressed», op. cit., pp. 43 y ss. 
no tengan en general acceso a las relaciones sociales fundadas en la propiedad inmobiliaria ya que sus derechos constituidos en las comunidades marginales son declarados ilegales por el sistema legal oficial. De este modo, a pesar de que en términos de estructura de superficie los conflictos tratados por el derecho de Pasargada fuesen creados, discutidos y resueltos como conflictos intraclasistas, en términos de estructura profunda son expresiones reffejas de un conflicto interclasista mucho más vasto. $Y$ esta dualidad implícita se halla siempre presente en el derecho de Pasargada en la medida en que la seguridad de las relaciones jurídicas es una garantía del desarrollo interno de la comunidad frente a la «comunidad del asfalto». En la realidad, cuanto mayor sea este desarrollo interno menor será la probabifidad de que los intereses capitalistas en la especulación de los terrenos urbanos presionen con éxito al Estado en el sentido de la destrucción de la favela y del trasłado de la comunidad a los suburbios de la ciudad (como ha sucedido más de una vez con otras favelas). En segundo lugar, el derecho de Pasatgada se centra alrededor de una organización elegida por la comunidad, una asociación de vecinos. A pesar de las limitaciones del proceso electoral, el derecho de Pasargada apunta, de esta manera, a una Administración de justicia alternativa y democrática, tanto más notable por cuanto tiene lugar en las franjas de un estado de tipo fascista. Si no puede llegar a más, desempeña cuando menos una función educativa y puede contribuir a elevar la conciencia de clase de las clases trabajadoras urbanas que viven en los bartios de chabolas. En tercer lugar, el derecho de Pasargada no forma parte de una estrategia revolucionaria organizada ni tiene lugar en una situación revolucionaria. Al contrario, se limita a minimizat la brutalidad de la teproducción social de las clases trabajadoras en condiciones de lucha muy difíciles. Teniendo a la vista tales condiciones -que son a la postre las condiciones prevalentes sobre todo en los países capitalistas periféricos o en el llamado tercer mundo-, puede argumentarse que un poder dual complementario o paralelo es la prehistoria de un poder dual confrontacional.

\section{CONCLUSION}

En este trabajo he explorado algunos modos posibles de extender el concepto de poder dual con referencia específica a las funciones judiciales del aparato de Estado. No pienso haber sido exhaustivo. Por el contrario, soy perfectamente consciente de que entre los dos casos extremos aquí analizados -tribunales populares y derecho de Pasargada- existe un 
número inffnito de casos intermedios. A guisa de ejemplo, mencionaré solamente los tribunales de vecinos organizados en los barrios de chabolas de Santiago, durante el gobierno Allende y con el apoyo de éste.

Considerando las implicaciones recíprocas de las cuestiones teóricas y estratégicas en el marxismo, el trabajo conceptual debe tener en cuenta las condiciones, siempre cambiantes, de la lucha socialista en el mundo y en especial (para lo que nos importa aqui y abora) en la Europa de hoy, tanto en los países centrales como en los periféricos. Siempre que una detnolición global del Estado clasista quede fuera de cuestión, una estrategia socialista realista debe comenzar por la redefinición del propio Estado. La estructura no monolítica y contradictoria del Estado debe ser estudiada detalladamente; los modos de determinación específicos a cada uno de sus sectores deben ser analizados bien de cerca; las estrategias del poder dual deben entonces ser organizadas en aquellos sectores donde las condiciones son más favorables.

Esta orientación estratéfica no presupone el techazo de la legalidad burguesa democrática ni de la democracia parlamentaria en cualquier lugar en que exista. Presupone más bien la posibilidad de una utilización no burguesa de las formas políticas y jurídicas democráticas que la burguesía supo en un tiempo imponer a las clases dominantes del ancien régime. En las presentes condiciones del Sur de Europa, por ejemplo, particularmente en Portugal, es evidente que compete a la clase obrera defender la legalidad democrática y la democracia parlamentaria, colocando las formas jurídico-políticas de otigen burgués al servicio de objetivos no burgueses. Semejante estrategia implica una lucha desigual, pero dada la naturaleza contradictoria de esas formas jurídicas y políticas, tal desigualdad es, en sí misma, dinámica y fuente de nuevas condiciones de lucha. El objetivo estratégico es agudizar las contradicciones en sectores específicos de la acción estatal hasta el punto de que las formas y los instrumentos políticos y juridicos burgueses se vuelvan no teproductivos del dominio de clase más allá de los límites de la disfuncionalidad controlable.

\section{Boaventura de Sousa Santos}

Facultad de Economía

Universidad de Coimbra

Coimbra (Portugal) 